\title{
Chemically activated poly(furfuryl alcohol)-derived CMK-3 carbon catalysts for the oxidative dehydrogenation of ethylbenzene
}

\author{
Paula Janus ${ }^{1}$, Rafał Janus ${ }^{1}$, Piotr Kuśtrowski ${ }^{*}, 1$, Sebastian Jarczewski ${ }^{1}$, Anna Wach ${ }^{1}$, \\ Ana M. Silvestre-Albero², Francisco Rodríguez-Reinoso ${ }^{2}$
}

${ }^{1}$ Department of Chemical Technology, Faculty of Chemistry, Jagiellonian University, Ingardena 3, 30-060 Kraków, Poland

${ }^{2}$ Departamento de Química Inorgánica, Universidad de Alicante, Apartado 99, E-03080 Alicante, Spain

\begin{abstract}
The surface of CMK-3 carbon, synthesized by the reversible replication of mesoporous silica (SBA-15) using poly(furfuryl alcohol) as a carbon precursor, was activated by wet oxidation with an aqueous solution of $\mathrm{HNO}_{3}$ or $\mathrm{H}_{2} \mathrm{O}_{2}$. The process was performed at $50^{\circ} \mathrm{C}$ using solution containing different concentrations of the oxidizing agent. It was found that during the modification no significant changes in textural and structural properties of CMK-3 replica occurred. However, the treatment resulted in the formation of appreciable amounts of surface species containing oxygen. XPS and DRIFT spectroscopy allowed to identify and quantify the surface functional groups. Their stability was studied by TG-FTIR measurements. $\mathrm{CO}$ and $\mathrm{CO}_{2}$ were found as main gaseous products evolved during thermal decomposition under inert atmosphere. Finally, the modified samples were tested in the catalytic oxidative dehydrogenation
\end{abstract}

\footnotetext{
* Corresponding author. Tel. +48 12 6632006. Fax +48 12 6340515. E-mail address: kustrows@chemia.uj.edu.pl (P. Kuśtrowski)
} 
of ethylbenzene to styrene at $350^{\circ} \mathrm{C}$ in the presence of oxygen as an oxidizing agent (at $\mathrm{O}_{2}$ /ethylbenzene molar ratio of 1.0 and 3.0). At the beginning of the catalytic run, the highest styrene yield and selectivity was achieved at the lower $\mathrm{O}_{2}$ content over the catalysts treated with nitric acid. Nevertheless, all studied catalysts underwent a gradual deactivation due to coke formation and changes in the distribution of surface moieties.

Keywords: mesoporous carbon, CMK-3, surface activation, oxidative dehydrogenation, ethylbenzene

\section{Introduction}

Oxidative dehydrogenation of ethylbenzene (EB) was proposed as an alternative route of styrene production in the late 1960s [1]. This method omits thermodynamic limitations and huge energy consumption typical of the commercial technology based on equilibrium-controlled dehydrogenation of EB performed in the presence of an excess of water vapor. In general, prospective catalysts for the oxidative dehydrogenation (ODH) of $\mathrm{EB}$, reported extensively in the literature, include either redox- or acidic-type systems. Among the redox catalysts, $\mathrm{MgO}-\mathrm{V}_{2} \mathrm{O}_{5}$ system, exhibiting surface clusters of $\mathrm{V}^{5+}$ and $\mathrm{V}^{4+}$ cations in octahedral coordination, is considered as the most active in this process [2,3]. On the other hand, a specific induction period of several hours to reach the steady state is observed in ODH of EB for the materials containing medium strength acid sites (e.g. alumina, zeolites) [2,4]. Over the last decades, it has been clearly evidenced that a coke layer, being formed at the beginning of the reaction, plays the role of the active phase in such acidic materials [4-7]. The superficial carbonyl/quinone groups were recognized as the active sites of $\mathrm{ODH}$ in this so called 'active coke' mechanism [8]. Consequently, carbon materials, which exhibit such surface species, are expected to be effective catalysts for ODH of EB to styrene $[9,10]$. This suggestion was confirmed by the study on the 
catalytic performance of various types of carbon materials (e.g. activated carbons, carbon nanofibers/nanotubes and onion-like carbons) [9,11-13].

Generally, the carbon-based catalysts have attracted a lot of researchers' interest due to numerous modifications which open possibilities of their application in many technologies by tailoring textural properties and surface composition [14]. Various activating agents (including $\mathrm{CO}_{2}$, alkali metal hydroxides) were previously used to improve the textural parameters of carbons [15-17]. The above mentioned reactants develop porosity and specific surface area of carbon materials, but have a very limited influence on the distribution of surface species [18-19]. For this reason, carbons activated by this way were often tested as the adsorbents of small molecules, especially in gas storage $\left(\mathrm{CO}_{2}, \mathrm{H}_{2}\right)$ [20-22]. On the other hand, mild oxidants can be also applied for the modification of carbon surface. Among the tested modifiers, both liquid (e.g. $\mathrm{NaOCl}, \mathrm{H}_{2} \mathrm{O}_{2}$, $\mathrm{HNO}_{3}, \mathrm{H}_{2} \mathrm{SO}_{4}$ ) and gaseous agents (e.g. $\mathrm{N}_{2} \mathrm{O}, \mathrm{H}_{2} \mathrm{O}, \mathrm{O}_{2}$ ) can be found [18,23-26]. The surface treatment with these activators usually results in the introduction of oxygen-containing surface moieties, such as carboxyl, carbonyl, phenolic, quinone and/or lactone [14,18,27].

In our previous paper [28] we reported the high catalytic activity of polymer-derived CMK-3 carbon replica in ODH of EB. It was postulated that the oxygen-containing surface groups play a crucial role in this process. This observation inspired us to continue the research with an additional oxidation of the CMK-3 surface. We decided to carry out the wet oxidation of the CMK-3 surface, which should improve its catalytic activity. In this work, the results of chemical treatment, using hydrogen peroxide and nitric acid as the oxidizing agents, are discussed. The activated materials were characterized by various physicochemical methods, which revealed the influence of the modification on the structure, texture and chemical surface composition of CMK-3. The catalytic behavior of the modified mesoporous carbon replicas in ODH of EB at different reaction conditions was studied. 


\section{Experimental}

\subsection{Synthesis}

CMK-3 carbon replica was synthesized according to the procedure described earlier by Niebrzydowska et al. [28]. Briefly, poly(furfuryl alcohol) (PFA) was deposited in the channel system of SBA-15 by the precipitation polycondensation of furfurol (FA, 98\%, Aldrich) performed in an aqueous slurry of silica template containing $\mathrm{HCl}$ (33\%, Polish Chemical Reagents). Amounts of $3.0 \mathrm{~g}$ of freshly calcined silica matrix, $6.0 \mathrm{~g}$ of FA and $94.0 \mathrm{~g}$ of distilled water were introduced into a round-bottom flask $\left(250 \mathrm{~cm}^{3}\right)$ equipped with a reflux condenser and placed on a magnetic stirrer. The slurry was stirred for $0.5 \mathrm{~h}$ at room temperature. Subsequently, an appropriate volume of $\mathrm{HCl}$ was added (at the $\mathrm{HCl} / \mathrm{FA}$ molar ratio of 6:1), and the mixture was heated up to $100^{\circ} \mathrm{C}$ and kept at this temperature under vigorous stirring for $6 \mathrm{~h}$. The obtained brown solid was filtered, washed with distilled water and dried overnight at room temperature. The obtained PFA/silica composites were carbonized in a tubular furnace under a flow of inert gas $\left(\mathrm{N}_{2}, 40 \mathrm{~cm}^{3} / \mathrm{min}\right)$ at $850^{\circ} \mathrm{C}$ with a heating rate of $1^{\circ} \mathrm{C} / \mathrm{min}$ and an isothermal period of $4 \mathrm{~h}$. Finally, the silica hard template was removed by twice treatment with a $5 \%$ hydrofluoric acid solution at room temperature. The resulting CMK-3 carbon replica was isolated, washed with distilled water and ethanol (96\%, Aldrich) and dried at $40^{\circ} \mathrm{C}$ overnight. The final material is marked as CMK-3.

CMK-3 surface was oxidized by the contact with aqueous solution containing 10, 20 and 30 wt.\% of hydrogen peroxide or 20,40 and $65 \%$ of nitric acid. The activation was performed in a roundbottom flask $\left(50 \mathrm{~cm}^{3}\right)$ at $50^{\circ} \mathrm{C}$ for $3 \mathrm{~h}$ by contacting $1.0 \mathrm{~g}$ of CMK-3 with $10 \mathrm{~cm}^{3}$ of the oxidizing solution. The resulting product was filtered, washed with distilled water until neutral $\mathrm{pH}$ and dried at $110^{\circ} \mathrm{C}$ for $5 \mathrm{~h}$. The obtained samples are labeled as $\mathrm{CMK}-3-\mathrm{HNO}_{3}-\chi$ or $\mathrm{CMK}-3-\mathrm{H}_{2} \mathrm{O}_{2}-\chi$ (where $x$ is the concentration of oxidant solution used for the modification). 


\subsection{Characterization}

The textural parameters of the materials were determined by means of low-temperature adsorption of nitrogen $\left(-196^{\circ} \mathrm{C}\right)$. The adsorption-desorption isotherms were collected in an ASAP 2020 instrument (Micromeritics). The obtained data were analyzed using the Brunauer-EmmettTeller (BET; specific surface area) and quenched solid density functional theory (QSDFT; pore size distribution as well as micro- and mesopore volumes) models.

The structure of the samples was investigated by X-ray powder diffraction (XRD) using a Bruker D2 Phaser instrument equipped with a LYNXEYE detector. The diffraction patterns were collected using $\mathrm{CuK} \alpha$ radiation $(\lambda=1.54184 \AA)$ in a $2 \theta$ range of $0.75 \div 3.00^{\circ}$ with a step of $0.02^{\circ}$. Transmission electron microscopy (TEM) imaging was studied with a JOEL microscope (model JEM-2010) equipped with an INCA Energy TEM 100 analytical system and a SIS MegaView II camera, working at $200 \mathrm{kV}$. Prior to the experiments, the sample was suspended in ethanol and placed on copper grids with a carbon film support (LASEY).

TG measurements were carried out with a SDT Q600 thermobalance (TA Instruments) for an amount of about $10 \mathrm{mg}$ of a sample placed in a corundum crucible. The sample was heated in nitrogen atmosphere (a flow rate of $100 \mathrm{~cm}^{3} / \mathrm{min}$ ) from $30^{\circ} \mathrm{C}$ to $1000^{\circ} \mathrm{C}$ at a heating rate of $10^{\circ} \mathrm{C} / \mathrm{min}$. The composition of the gaseous products evolved during thermal decomposition was investigated using a TG/FTIR interface (Thermo Scientific) connected on-line with a Nicolet 6700 (Thermo Scientific) FTIR spectrometer. The spectra were collected in a middle-infrared region of $650-4000 \mathrm{~cm}^{-1}$ at a resolution of $4 \mathrm{~cm}^{-1}$ and a time interval of $3 \mathrm{~s}$.

X-ray photoelectron spectroscopy (XPS) measurements were performed with a Prevac photoelectron spectrometer equipped with a hemispherical analyzer (VG SCIENTA R3000). The spectra were taken using a monochromatized aluminum source $\mathrm{AlK} \alpha(\mathrm{E}=1486.6 \mathrm{eV})$. The base pressure in the analytical chamber was $5 \cdot 10^{-9}$ mbar. The binding energy scale was calibrated using the Au $4 \mathrm{f}_{7 / 2}$ line of a cleaned gold sample at $84.0 \mathrm{eV}$. The surface composition was 
analyzed taking into account the areas and binding energies of $\mathrm{C} 1 \mathrm{~s}, \mathrm{O} 1 \mathrm{~s}$ and $\mathrm{N} 1 \mathrm{~s}$ core levels. The spectra were fitted using the CasaXPS software.

DRIFT spectra were collected without sample dilution in the Nicolet 6700 FTIR spectrometer equipped with a DRIFT device (EasiDiff ${ }^{\mathrm{TM}}$-Pike Technologies) and a MCT-A detector with 200 scans at a resolution of $4 \mathrm{~cm}^{-1}$. The spectrum of the unmodified CMK-3 sample was used as background and subtracted from the spectra measured for the activated samples.

\subsection{Catalytic tests}

The catalytic tests were performed in a flow-type quartz reactor filled with $50 \mathrm{mg}$ of a sample placed on a quartz wool plug. The gaseous reactants were fed using mass flow controllers (Brooks 4800) at a total flow of $50 \mathrm{~cm}^{3} / \mathrm{min}$, which contained 0.8 or 2.4 vol.\% of $\mathrm{O}_{2}$, diluted in helium, corresponding to the $\mathrm{O}_{2}$ :EB molar ratio of 1.0 and 3.0, respectively. EB was introduced into the reaction mixture by saturation of the $\mathrm{He}+\mathrm{O}_{2}$ stream in a glass saturator filled with liquid EB kept at $25^{\circ} \mathrm{C}$. The reaction products were sampled with a Valco six-port valve and transferred to analysis in a gas chromatograph (Bruker 450-GC) via a heated line. GC was equipped with three packed columns (Porapak Q, Molecular Sieve 5A and Chromosorb W-HP) and three detectors (two flame ionization detectors - including one coupled with catalytic methanizer - and thermal conductivity detector).

Prior to the catalytic run, each sample was outgassed at $200^{\circ} \mathrm{C}$ for $30 \mathrm{~min}$. in a flow of helium (50 $\mathrm{cm}^{3} / \mathrm{min}$ ). Subsequently, the temperature of catalyst bed was increased to $350^{\circ} \mathrm{C}$ and dosing of EB and $\mathrm{O}_{2}$ started. The first GC analysis was carried out after 15 min. time-on-stream. The total reaction time was $7 \mathrm{~h}$, and the products were analyzed at $40 \mathrm{~min}$. intervals. The catalytic performance was evaluated in terms of the following parameters:

$$
X_{E B}=\frac{F_{E B, 0}-F_{E B}}{F_{E B, 0}} \cdot 100 \%
$$




$$
\begin{aligned}
& Y_{i}=\frac{F_{i}}{F_{E B, 0}} \cdot 100 \% \\
& S_{i}=\frac{Y_{i}}{X_{E B}} \cdot 100 \%
\end{aligned}
$$

where: $\mathrm{X}_{\mathrm{EB}}$ - conversion of ethylbenzene; $\mathrm{F}_{\mathrm{EB}, 0}$ and $\mathrm{F}_{\mathrm{EB}}$ - molar flow rate of $\mathrm{EB}$ in the inlet and outlet streams; $\mathrm{Y}_{\mathrm{i}}$ - yield of i product; $\mathrm{F}_{\mathrm{i}}$ - molar flow rate of EB transformed into i product, $\mathrm{S}_{\mathrm{i}}-$ selectivity of i product.

\section{Results and discussion}

\subsection{Structural and textural properties of unmodified CMK-3}

The low-temperature $\mathrm{N}_{2}$ adsorption-desorption isotherm recorded for the unmodified CMK-3 sample (Fig. 1A) corresponds to type IV as classified by the IUPAC. It exhibits a well-defined capillary condensation step at relative pressures $\mathrm{p} / \mathrm{p}_{0}$ between 0.30 and 0.55 , indicating uniform mesoporosity [29]. The calculated BET specific surface area $\left(\mathrm{S}_{\mathrm{BET}}=1120 \mathrm{~m}^{2} / \mathrm{g}\right)$ and total pore volume $\left(\mathrm{V}_{\text {total }}=0.79 \mathrm{~cm}^{3} / \mathrm{g}\right)$ are comparable with the values of these parameters published previously for CMK-3 materials [30,31]. It should be noticed that the porosity of the studied carbon replica is constituted of both micropores $\left(\mathrm{V}_{\text {micro }}=0.21 \mathrm{~cm}^{3} / \mathrm{g}\right)$ and mesopores $\left(\mathrm{V}_{\text {meso }}=\right.$

$0.58 \mathrm{~cm}^{3} / \mathrm{g}$ ). The pore size distribution (Fig. 1A, inset) calculated basing on the equilibrium QSDFT model reveals two maxima, which can be assigned to micro-mesoporosity with average diameters of micro- and mesopores equal to 1.1 and $2.8 \mathrm{~nm}$, respectively. Such bimodal porosity is characteristic of polymer-derived carbon mesoporous materials [32,33].

The XRD pattern collected for unmodified CMK-3, presented in Fig. 1B, shows three well resolved Bragg diffraction peaks at $1.06^{\circ}, 1.83^{\circ}$ and $2.09^{\circ} 2 \theta$, which can be indexed as (100), (110) and (200) reflections associated with p6mm hexagonal symmetry [31,34,35]. The determined value of $\mathrm{d}_{100}$ spacing is equal to $8.3 \mathrm{~nm}$, and corresponds to unit cell parameter $\mathrm{a}=$ 
$9.6 \mathrm{~nm}\left(a=\frac{2 d_{100}}{\sqrt{3}}\right)$. TEM micrographs of CMK-3 (Fig. 1C and 1C') reveal the hexagonal arrangement of carbon nanorods interconnected by carbon spacers. Such structure is typical of CMK-3 carbon replica, which was described first time by Jun et al. [36].

\subsection{Influence of treatment with oxidizing agents on pore structure of CMK-3}

The changes in the textural and structural properties of CMK-3 caused by its treatment with different oxidizing agents $\left(\mathrm{H}_{2} \mathrm{O}_{2}\right.$ or $\left.\mathrm{HNO}_{3}\right)$ were studied by low temperature $\mathrm{N}_{2}$ adsorptiondesorption as well as powder X-ray diffraction. The collected isotherms and calculated pore size distributions are presented in Supplementary data (cf. Fig. S1A-S1B and S2A-S2B), whereas the determined surface areas $\left(\mathrm{S}_{\mathrm{BET}}\right)$ as well as micropore $\left(\mathrm{V}_{\text {micro }}\right)$ and mesopore $\left(\mathrm{V}_{\text {meso }}\right)$ volumes are shown in Table 1.

The presented data reveal that the performed modifications have no meaningful effect on the textural parameters of the carbon replica. The treatment with more concentrated solutions of oxidants led to the highest decrease in the textural parameters. However, the $\mathrm{S}_{\mathrm{BET}}$ value drops after the modification less than $6 \%$. The highest changes are observed for mesoporosity of the $\mathrm{HNO}_{3}$-treated samples, which lost about $10 \%$ of $\mathrm{V}_{\text {meso }}$. This effect can be explained by a slight collapse of carbon mesostructure caused by a partial destruction of unstable carbon spacers. On the other hand, the pore size distributions show that the average micro- and mesopore diameters for all samples after the modifications are preserved at 1.1 and $2.8 \mathrm{~nm}$, respectively.

The XRD patterns for both series of modified CMK-3 samples are demonstrated in Fig. S1C and S2C in Supplementary data. In all cases the three well-resolved (100), (110) and (200) diffraction peaks can be distinguished. Table 1 shows the calculated $d_{100}$ and a parameters for the CMK-3 samples after the treatment under oxidizing conditions. As can be seen, both oxidants do not 
cause any significant changes in the aforementioned parameters compared to the values determined for unmodified CMK-3.

Thus, the nitrogen adsorption and XRD measurements provide the conclusion that the modifications at the selected conditions do not destroy considerably the pore structure of the CMK-3 replica.

\subsection{Surface composition of modified CMK-3 replica}

The chemical composition of the CMK-3 surface before and after the modification with $\mathrm{HNO}_{3}$ and $\mathrm{H}_{2} \mathrm{O}_{2}$ was examined by DRIFT, XPS as well as TG-FTIR measurements.

The DRIFT spectra recorded for the undiluted samples after subtracting the spectrum of the parent carbon replica are displayed in Fig. 2. It is clearly shown that the treatment with the used activators oxidized the surface of CMK-3, what is manifested by an increase in the intensities of IR bands observed in the range between 1100 and $1800 \mathrm{~cm}^{-1}$. The band at $1763 \mathrm{~cm}^{-1}$ is assigned to the $\mathrm{C}=\mathrm{O}$ stretching vibrations in lactone, carboxylic anhydride and/or carboxylic acid, while the absorption at $1233 \mathrm{~cm}^{-1}$ is attributed to the C-O stretching vibrations in ether, lactone, phenol and/or carboxylic anhydride [18,37-40]. The band at $1587 \mathrm{~cm}^{-1}$ can be ascribed to the C-C stretching vibrations in aromatic ring as well as quinone and keto-enol groups $[18,37,39,40]$. Broad complex bands in the range of $1300-1450$ and $1100-1300 \mathrm{~cm}^{-1}$ correspond to the C-H bending vibrations (in $-\mathrm{CH}_{2}$ and $-\mathrm{CH}_{3}$ groups) and stretching vibrations of carbonyl and ether moieties, respectively [39-41]. The spectra collected for the samples modified with nitric acid exhibit the additional absorption bands at 1355 and $1568 \mathrm{~cm}^{-1}$ providing the presence of nitro groups on the carbon surface [39-42]. It is noteworthy that the intensity of the discussed above bands increases with concentration of the oxidizing agent suggesting a higher content of surface oxygen-containing groups compared to the unmodified sample. 
The O 1s spectra of CMK-3 and the samples after the modifications are displayed in Fig. 3 and the contributions of particular C-, O- and N-containing species are summarized in Table 2. The O 1s core level spectra were fitted with four peaks at $531.0 \mathrm{eV}$ ( $\mathrm{C}=\underline{\mathrm{O}}$ in quinone), $532.7 \mathrm{eV}$ (oxygen in hydroxyl, ether, ester, anhydride and carboxyl (ㅁH, $\mathrm{C} \underline{\mathrm{OOH}})$ as well as oxygen in nitro group bonded to aromatic ring (N-ㅁ)), $534.4 \mathrm{eV}$ (ether oxygen in ester and anhydride as well as hydroxyl in carbonyl group (COOHH)) and $537.0 \mathrm{eV}$ (adsorbed water) [8,43-45]. The chemical structures of the above mentioned oxygen-containing moieties are shown in Fig. 4. The structures ascribed to the peaks located at 531.0, 532.7 and $534.4 \mathrm{eV}$ are denoted as (1), (2) and (3), respectively. The C 1s core level spectra (not shown) were deconvoluted into four peaks: (i) carbon atom in graphitic and disordered carbon species $\left(\underline{\mathrm{C}}=\underline{\mathrm{C}} \mathrm{sp}^{2}\right.$ and $\left.\underline{\mathrm{C}}-\underline{\mathrm{C}} \mathrm{sp}^{3}\right)$ with binding

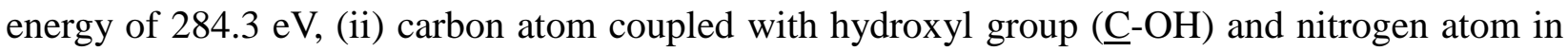
nitro group ( $\underline{\mathrm{C}}-\mathrm{N})(286.3 \mathrm{eV})$, (iii) carbon atom in carbonyl group $(\underline{\mathrm{C}}=\mathrm{O})(287.5 \mathrm{eV})$, (iv) carbon atom in carboxyl group $(\underline{\mathrm{COOH}})(288.5 \mathrm{eV})$ [8,43-45]. The peak with binding energy of $290.0 \mathrm{eV}$ corresponds to shake-up satellite due to $\pi-\pi^{*}$ transitions in aromatic rings, which confirms the polyaromatic character of the studied carbon replica [39,43]. In the case of $\mathrm{N} 1 \mathrm{~s}$ core level spectra (not shown) one identified peak with binding energy of $405.6 \mathrm{eV}$ can be assigned to nitrogen atom in nitro group $\left(\mathrm{C}-\underline{\mathrm{NO}}_{2}\right)$ [8,45-47].

The differential mass changes (DTG), measured for the parent and modified CMK-3 samples during thermal desorption of surface functional groups at the inert atmosphere, are shown in Fig. 5A. Regardless of the oxidazing agent used, all the collected DTG profiles exhibit two main decomposition steps in the temperature range of $150-500^{\circ} \mathrm{C}$ and $500-900^{\circ} \mathrm{C}$, respectively. Nevertheless, the shape of the DTG curves depends strongly on the applied oxidant and its concentration. The mass loss increases noticeably with the concentration of oxidizing agent confirming the results of DRIFT and XPS measurements, which revealed the higher content of surface groups after treatment with the more concentrated solution of oxidant. Furthermore, an 
additional DTG peak is observed at about $420^{\circ} \mathrm{C}$ for the samples activated with $\mathrm{HNO}_{3}$. The distinct maxima at about 290 and $420^{\circ} \mathrm{C}$ in the case of this series of samples can be assigned to strong and weak acidic carboxylic groups, respectively $[44,48]$. The gaseous products evolved during thermal decomposition of surface oxygen-containing moieties were analyzed by FTIR spectroscopy. As can be seen in Fig. 5B and 5C, two main products formed by desorption of

surface functionalities are CO (band at $2183 \mathrm{~cm}^{-1}$ ) and $\mathrm{CO}_{2}$ (band at $2358 \mathrm{~cm}^{-1}$ ). At the lowtemperature decomposition step $\left(150-500^{\circ} \mathrm{C}\right), \mathrm{CO}_{2}$ is predominantly evolved, indicating decomposition of acidic carboxylic groups [37,44,48]. Raising temperature results in the intensification of $\mathrm{CO}$ emission, which can be assigned to decomposition of carboxylic anhydrides, phenolic, quinone and lactone moieties $[8,37,44]$. It is especially noteworthy that the treatment with $\mathrm{HNO}_{3}$ causes the formation of significantly higher amounts of carboxylic groups compared to activation with $\mathrm{H}_{2} \mathrm{O}_{2}$. Similar effect was discussed earlier by Moreno-Castilla et al. [49] who studied the influence of the type of oxidizing agent on the surface chemistry of activated carbon modified by wet oxidation using ammonium persulfate, hydrogen peroxide and nitric acid. The experiments exhibited that the concentration of oxygen-containing groups and surface acidity of modified samples increased in the following order: $\left(\mathrm{NH}_{4}\right)_{2} \mathrm{~S}_{2} \mathrm{O}_{8}<\mathrm{H}_{2} \mathrm{O}_{2}<$ $\mathrm{HNO}_{3}$

\subsection{Catalytic activity of modified CMK-3 replica in ODH of EB}

The CMK-3 carbon replica treated with $\mathrm{HNO}_{3}$ and $\mathrm{H}_{2} \mathrm{O}_{2}$ was tested as a catalyst of ODH of EB in the presence of oxygen $\left(\mathrm{O}_{2}\right.$ :EB molar ratio $=1.0$ or 3.0$)$. All the studied catalysts showed a high catalytic activity at $350^{\circ} \mathrm{C}$. This reaction temperature was chosen as optimal for the parent sample in our previous work [28]. Over the studied catalysts under the reaction conditions, styrene and $\mathrm{CO}_{\mathrm{x}}$ were mainly formed, and only traces of other products were detected. The catalytic performance of the parent and modified CMK-3 materials measured at the beginning of 
catalytic run (after 15 min. time-on-stream) is presented in Table 3. It could be noticed that activation of CMK-3 with the oxidizing agents has a beneficial effect on the styrene yield. At the $\mathrm{O}_{2}$ :EB molar ratio of 1.0 , the increase in the styrene yield from $21.4 \%$ to $24.9-25.6 \%$ (in the case of $\mathrm{H}_{2} \mathrm{O}_{2}$-activated samples) or $28.0-31.1 \%$ (in the case of $\mathrm{HNO}_{3}$-activated samples) is observed. For the reaction performed at the higher oxygen content $\left(\mathrm{O}_{2}: \mathrm{EB}\right.$ molar ratio of 3.0), this effect is less evident $-23.5 \%$ of the styrene yield for the parent CMK-3, 25.0-28.7\% - for CMK-3 modified with $\mathrm{H}_{2} \mathrm{O}_{2}$ and 26.8-29.1\% - for CMK-3 modified with $\mathrm{HNO}_{3}$. Taking into account the higher selectivity towards the total oxidation products found at the higher $\mathrm{O}_{2}$ content, it should be concluded that performing the ODH process at $\mathrm{O}_{2}$ :EB molar ratio of 1.0 is more favorable.

Regardless of the reaction conditions, the CMK-3 catalysts undergo a gradual deactivation with time-on-stream (Fig. 6). This effect is more distinct for the materials pre-activated with $\mathrm{H}_{2} \mathrm{O}_{2}$ or $\mathrm{HNO}_{3}$ than for pristine CMK-3. After several hours of catalytic run, very similar yields of styrene and $\mathrm{CO}_{\mathrm{x}}$ are achieved over the differently modified samples. The main reason of observed deactivation is the formation of carbon deposit, which limits accessibility of reactants to active sites. Figure 7 presents the comparison of textural properties of fresh CMK-3 as well as CMK-3, CMK-3- $\mathrm{H}_{2} \mathrm{O}_{2}-30$ and $\mathrm{CMK}-3-\mathrm{HNO}_{3}-65$ after 7 hours of time-on-stream at the molar ratio of $\mathrm{O}_{2}: \mathrm{EB}=1: 1$. An evident decrease in the pore volume and the surface area is observed for the spent catalysts. However, all samples show nearly the same pore size distribution, which indicates clogging of pores by carbon deposit mainly at their mouths. The loss of textural parameters of CMK-3 replicas treated with $\mathrm{HNO}_{3}$ can be attributed to their acidity, since these samples possess the highest number of oxygen-containing functionalities on the surface (cf. Fig. 5 and Table 2).

On the other hand, the TG study showed (cf. Fig. 5) that decomposition of oxygen-containing groups begins at temperature as low as about $150^{\circ} \mathrm{C}$. It should therefore be expected that during the catalytic run at $350^{\circ} \mathrm{C}$ a part of functionalities present on the carbon surface is removed. The 
lines illustrating DTG and evolution of $\mathrm{CO} / \mathrm{CO}_{2}$ formed as gaseous products during thermal decomposition of the spent catalysts, presented in Fig. S3, confirm this assumption. A very distinct re-organization of surface content occurs in the course of catalytic reaction. For unmodified CMK-3, a huge amount of new sites appears, especially after the reaction at the molar ratio of $\mathrm{O}_{2}: \mathrm{EB}=3: 1$, which is effective in the formation of species decomposed into $\mathrm{CO}_{2}$. In the case of $\mathrm{H}_{2} \mathrm{O}_{2}$ - and $\mathrm{HNO}_{3}$-modified CMK-3, a disappearance of low stable oxygencontaining groups (mainly carboxylic) is observed. Simultaneously, more stable functionalities are formed. The quantification of surface oxygen-containing species is possible due to the XPS measurements. The content of different forms of oxygen on the surface of fresh CMK-3, CMK-3$\mathrm{H}_{2} \mathrm{O}_{2}-30$ and CMK-3- $\mathrm{HNO}_{3}-65$ as well as these samples after 7 hours of time-on-stream is shown in Table 4. It is found that the amount of surface functionalities increases after the catalytic run for the CMK-3 catalyst. The higher partial pressure of $\mathrm{O}_{2}$ in the reaction mixture promotes the surface oxidation. The opposite effect is observed for the modified CMK-3 samples, which lost a part of surface species during the catalytic run. It is especially noteworthy that under the reaction conditions the relative content of different oxygen-containing moieties changed. The increase in the contribution of oxidized species (mainly quinone and carboxylic) and the decrease in the relative content of hydroquinone-like groups is detected.

The high content of quinone-like species in the fresh, modified catalysts (especially the samples after the treatment with $\mathrm{HNO}_{3}$ ) is probably responsible for their catalytic activity in the ODH process. Such moieties are widely considered as catalytically active in carbon-based catalysts $[4,7-9,50]$. In the first step of the postulated mechanism, ethylbenzene molecule interacts with two adjacent quinone-like groups with the abstraction of hydrogen and the production of styrene molecule. Subsequently, resulting hydroquinone species are re-oxidized in the presence of oxygen to form $\mathrm{H}_{2} \mathrm{O}$ and active quinone-like sites. 


\section{Conclusions}

Both $\mathrm{H}_{2} \mathrm{O}_{2}$ and $\mathrm{HNO}_{3}$ can be used for the effective, wet oxidation of surface of CMK-3 carbon replica. Nevertheless, the content and type of introduced functionalities depend on the kind of oxidizing agent and its concentration in the solution applied during the modification. The DRIFT and XPS measurements showed that the amount of oxygen-containing groups increases considerably with raising the concentration of $\mathrm{H}_{2} \mathrm{O}_{2}$ and $\mathrm{HNO}_{3}$ solution. On the other hand, the treatment with nitric acid results in deeper oxidation and a higher amount of carboxylic species appears on the carbon surface. These groups are less stable than phenolic, quinone and lactone moieties, and are decomposed at $350^{\circ} \mathrm{C}$ - temperature used during the catalytic tests. The activated CMK-3 samples appeared to be active catalysts in the oxidative dehydrogenation of ethylbenzene to styrene. The best catalytic performance was achieved at the molar ratio of $\mathrm{O}_{2}: \mathrm{EB}$ $=1: 1$ over the catalysts activated with $\mathrm{HNO}_{3}$. The beneficial effect of modification is attributed to the formation of quinone-type groups, which are probably active sites during the ODH process. The activity of the studied catalysts declined with time-on-stream, especially in the case of the samples treated with $\mathrm{H}_{2} \mathrm{O}_{2}$ or $\mathrm{HNO}_{3}$. The coke formation and the changes in the distribution of oxygen-containing groups on the catalyst surface caused that similar yields of styrene were observed after several hours of catalytic run over the differently modified samples.

\section{Acknowledgements}

This work was supported by the National Science Centre under the grant no. DEC2011/01/N/ST5/05595. The research was carried out with the equipment purchased thanks to the financial support of the European Regional Development Fund in the framework of the Polish Innovation Economy Operational Program (contract No. POIG.02.01.00-12-023/08). 


\section{References}

[1] O.K. Bogdanova, I.P. Belomestnykh, N.V. Voikina, A.A. Balandin, Petrol. Chem. U.S.S.R. 7 (1967) 186-190.

[2] W.S. Chang, Y.Z. Chen, B.L. Yang, Appl. Catal. A: Gen. 124 (1995) 221-243.

[3] W. Oganowski, J. Hanuza, L. Kepiński, Appl. Catal. A: Gen. 171 (1998) 145-154.

[4] F. Cavani, F. Trifirò, Appl. Catal. A: Gen. 133 (1995) 219-239.

[5] G.E. Vrieland, P.G. Menon, Appl. Catal. 77 (1991) 1-8.

[6] C. Nederlof, V. Zarubina, I. Melián-Cabrera, H.J. Heeres, F. Kapteijn, M. Makkee, Catal, Sci. Technol. 3 (2013) 519-526.

[7] G. Emig, H. Hofmann, J. Catal. 84 (1983) 15-26.

[8] J.L. Figueiredo, M.F.R. Pereira, Catal. Today 150 (2010) 2-7.

[9] M.F.R. Pereira, J.J.M. Órfão, J.L. Figueiredo, Appl. Catal. A: Gen. 184 (1999) 153-160.

[10] J.A. Maciá-Agulló, D. Cazorla-Amorós, A. Linares-Solano, U. Wild, D.S. Su, R. Schlögl, Catal. Today 102-103 (2005) 248-253.

[11] J.J. Delgado, X.W. Chen, B. Frank, D.S. Su, R. Schlögl, Catal Today 186 (2012) 93-98.

[12] M.F.R. Pereira, J.L. Figueiredo, J.J.M. Órfão, P. Serp, P. Kalck, Y. Kihn, Carbon 42 (2004) 2807-2813.

[13] N. Keller, N.I. Maksimova, V.V. Roddatis, M. Schur, G. Mestl, Y.V. Butenko, V.L. Kuznetsov, R. Schlögl, Angew. Chem. Int. Ed. 41 (2002) 1885-1888.

[14] F. Rodríguez-Reinoso, Carbon 36 (1998) 159-175.

[15] K. Xia, Q. Gao, J. Jiang, J. Hu, Carbon 46 (2008) 1718-1726.

[16] M. Enterría, F. Suárez-García, A. Martínez-Alonso, J.M.D. Tascón, Carbon 50 (2012) 38263835.

[17] M. Enterría, F. Suárez-García, A. Martínez-Alonso, J.M.D. Tascón, Micropor. Mesopor. Mater. 151 (2012) 390-396. 
[18] J.L. Figueiredo, M.F.R. Pereira, M.M.A. Freitag, J.J.M. Órfão, Carbon 37 (1999) 13791389.

[19] Q. Jiang, Y. Zhao, Micropor. Mesopor. Mater. 76 (2004) 215-219.

[20] K. Xia, Q. Gao, C. Wu, S. Song, M. Ruan, Carbon 45 (2007) 1989-1996.

[21] F. Liu, Z. Guo, S. Zheng, Z. Xu, Chem. Eng. J. 183 (2012) 244-252.

[22] S.M. Lee, S.C. Lee, W.G. Hong, H.J. Kim, Chem. Phys. Lett. 554 (2012) 133-136.

[23] J. Choma, W. Burakiewicz-Mortka, M. Jaroniec, Z. Li, J. Klinik, J. Colloid Interf. Sci. 214 (1999) 438-446.

[24] A.H. Lu, W.-C. Li, N. Muratora, B. Spliethoff, F. Schüth, Chem. Commun. (2005) 51845186.

[25] N.D. Lysenko, P. S. Yaremov, A.V. Shvets, V.G. Il’in, Theor. Exp. Chem. 45 (2009) 380385.

[26] H.B. An, M.J. Yu, J.M. Kim, M. Jin, J.-K. Jeon, S.H. Park, S.-S. Kim, Y.-K. Park, Nanoscale Res. Lett. 7 (2012) 1-6.

[27] H. Marsh, F. Rodríguez-Reinoso, Activated carbon, first ed., Elsevier Ltd., UK, 2006.

[28] P. Niebrzydowska, R. Janus, P. Kuśtrowski, S. Jarczewski, A. Wach, A.M. Silvestre-Albero, F. Rodríguez-Reinoso, Carbon 64 (2013) 252-261.

[29] G.Y. Gor, M. Thommes, K.A. Cychosz, A.V. Neimark, Carbon 50 (2012) 1583-1590.

[30] A.B. Fuertes, Micropor. Mesopor. Mat. 67 (2004) 273-281.

[31] T. Onfroy, F. Guenneau, M.A. Springuel-Huet, A. Gédéon. Carbon 47 (2009) 2352-2357.

[32] R.K. Mariwala, H.C. Foley, Ind. Eng. Chem. Res. 33 (1994) 607-615.

[33] C.L. Burket, R. Rajagopalan, A.P. Marencic, K. Dronvajjala, H.C. Fole, Carbon 44 (2006) 2957-2963.

[34] W. Schmidt, Micropor. Mesopor. Mater. 117 (2009) 372-379. 
[35] L. Calvillo, V. Celorrio, R. Moliner, P.L. Cabot, I. Esparbé, M.J. Lázaro, Micropor. Mesopor. Mater. 116 (2008) 292-298.

[36] S. Jun, S.H. Joo, R. Ryoo, M. Kruk, M. Jaroniec, Z. Liu, T. Ohsuna, O. Terasaki, J. Am. Chem. Soc. 122 (2000) 10712-10713.

[37] A.M.T. Silva, B.F. Machado, J.L. Figueiredo, J.L. Faria, Carbon 47 (2009) 1670-1679.

[38] J. Roggenbuck, T. Waitz, M. Tiemann, Micropor. Mesopor. Mater. 113 (2008) 575-582.

[39] U. Zielke, K.J. Hüttinger, W.P. Hoffman, Carbon 34 (1996) 983-998.

[40] D. Stéfani, A.J. Paula, B.G. Vaz, R.A. Silva, N.F. Andrade, G.Z. Justo, C.V. Ferreira, A.G.S. Filho, M.N. Eberlin, O.L. Alves, J. Hazard. Mater. 189 (2011) 391-396.

[41] E. Vilaplana-Ortego, J. Alcañiz-Monge, D. Cazorla-Amorós, A. Linares-Solano, Carbon 41 (2003) 1001-1007.

[42] J. Zawadzki, M. Wiśniewski, K. Skowrońska, Carbon 41 (2003) 235-246.

[43] H. Darmstadt, C. Roy, S. Kaliaguine, S.J. Choi, R. Ryoo, Carbon 40 (2002) 2673-2683.

[44] A.Sánchez-Sánches, F. Suárez-Garcia, A. Martínez-Alonso, J.M.D. Tascón, Carbon 62 (2013) 193-203.

[45] J.M. Jimenez Mateos, J.L.G. Fierro, Surf. Interface. Anal. 24 (1996) 223-236.

[46] The XPS of Polymers Database edited by G. Beamson \& D. Briggs; Surface Spectra Ltd.

[47] R.P. Rocha, J. P.S. Sousa, A.M.T. Silva, M.F.R. Pereira, J.L. Figueiredo, Appl. Catal. BEnviron. 104 (2011) 330-336.

[48] J.L. Figueiredo, M.F.R. Pereira, M.M.A. Freitas, J.J.M. Órfão, Ind. Eng. Chem. Res. 46 (2007) 4110-4115.

[49] C. Moreno-Castilla, M.V. López-Ramón, F. Carrasco-Marín, Carbon 38 (2000) 1995-2001.

[50] M.F.R. Pereira, J.J.M. Órfão, J.L. Figueiredo, Appl. Catal. A: Gen.218 (2001) 307-318. 
Table 1. Textural and structural parameters of CMK-3 before and after the treatment with oxidizing agents.

\begin{tabular}{cccccc}
\hline & \multicolumn{3}{c}{ Textural parameters } & \multicolumn{2}{c}{ Structural parameters } \\
\cline { 2 - 5 } Sample & $\mathrm{S}_{\mathrm{BET}}$ & $\mathrm{V}_{\text {micro }}$ & $\mathrm{V}_{\text {meso }}$ & $\mathrm{d}_{100}[\mathrm{~nm}]$ & $\mathrm{a}[\mathrm{nm}]$ \\
& {$\left[\mathrm{m}^{2} / \mathrm{g}\right]$} & {$\left[\mathrm{cm}^{3} / \mathrm{g}\right]$} & {$\left[\mathrm{cm}^{3} / \mathrm{g}\right]$} & & \\
\hline $\mathrm{CMK}-3$ & 1120 & 0.21 & 0.58 & 8.3 & 9.6 \\
$\mathrm{CMK}-3-\mathrm{H}_{2} \mathrm{O}_{2}-10$ & 1096 & 0.21 & 0.59 & 8.2 & 9.4 \\
$\mathrm{CMK}-3-\mathrm{H}_{2} \mathrm{O}_{2}-20$ & 1053 & 0.20 & 0.58 & 8.3 & 9.6 \\
$\mathrm{CMK}-3-\mathrm{H}_{2} \mathrm{O}_{2}-30$ & 1059 & 0.20 & 0.59 & 8.2 & 9.4 \\
$\mathrm{CMK}-3-\mathrm{HNO}_{3}-20$ & 1119 & 0.21 & 0.56 & 8.3 & 9.6 \\
$\mathrm{CMK}-3-\mathrm{HNO}_{3}-40$ & 1098 & 0.21 & 0.54 & 8.3 & 9.6 \\
$\mathrm{CMK}-3-\mathrm{HNO}_{3}-65$ & 1065 & 0.19 & 0.53 & 8.3 & 9.6 \\
\hline
\end{tabular}


Table 2. Concentration of carbon, oxygen and nitrogen species on the surface of pristine and modified CMK-3 samples determined by XPS.

\begin{tabular}{|c|c|c|c|c|c|c|c|c|}
\hline \multirow{6}{*}{ Sample } & \multicolumn{8}{|c|}{ Atomic concentration [\%] } \\
\hline & \multicolumn{4}{|c|}{ Carbon } & \multicolumn{3}{|c|}{ Oxygen } & \multirow[t]{2}{*}{ Nitrogen } \\
\hline & \multirow{4}{*}{$\begin{array}{c}\underline{\mathrm{C}}=\mathrm{C} \\
\mathrm{sp}^{2} \\
\underline{\mathrm{C}}-\mathrm{C} \\
\mathrm{sp}^{3}\end{array}$} & \multirow{4}{*}{$\begin{array}{l}\underline{\mathrm{C}}- \\
\mathrm{OH} \\
\underline{\mathrm{C}}-\mathrm{N}\end{array}$} & \multirow{4}{*}{$\underline{\mathrm{C}}=\mathrm{O}$} & \multirow{4}{*}{$\underline{\mathrm{COOH}}$} & \multicolumn{3}{|c|}{$(2)$} & \\
\hline & & & & & (1) & $\underline{\mathrm{OH}}$ & (3) & \multirow{3}{*}{$\mathrm{C}-\mathrm{NO}_{2}$} \\
\hline & & & & & $\mathrm{C}=\underline{\mathrm{O}}$ & $\mathrm{CO} O H$ & $\mathrm{COO} H$ & \\
\hline & & & & & & $\mathrm{N}-\underline{\mathrm{O}}$ & & \\
\hline CMK-3 & 95.98 & 1.13 & 0.51 & 0.19 & 0.50 & 1.33 & 0.18 & - \\
\hline $\begin{array}{l}\text { CMK-3- } \\
\mathrm{H}_{2} \mathrm{O}_{2}-10\end{array}$ & 88.56 & 3.85 & 1.13 & 0.38 & 1.13 & 4.23 & 0.38 & - \\
\hline $\begin{array}{l}\text { CMK-3- } \\
\mathrm{H}_{2} \mathrm{O}_{2}-20\end{array}$ & 87.70 & 3.93 & 1.31 & 0.53 & 1.31 & 4.46 & 0.53 & - \\
\hline $\begin{array}{l}\text { CMK-3- } \\
\mathrm{H}_{2} \mathrm{O}_{2}-30\end{array}$ & 82.76 & 5.56 & 1.63 & 0.76 & 1.63 & 6.31 & 0.76 & - \\
\hline $\begin{array}{l}\text { CMK-3- } \\
\mathrm{HNO}_{3}-20\end{array}$ & 85.76 & 3.45 & 1.69 & 0.78 & 1.69 & 4.87 & 0.78 & 0.64 \\
\hline $\begin{array}{l}\text { CMK-3- } \\
\mathrm{HNO}_{3}-40\end{array}$ & 82.74 & 5.15 & 1.73 & 0.61 & 1.73 & 6.44 & 0.61 & 0.68 \\
\hline $\begin{array}{l}\text { CMK-3- } \\
\mathrm{HNO}_{3}-65\end{array}$ & 81.33 & 5.39 & 2.09 & 0.66 & 2.09 & 6.76 & 0.66 & 0.71 \\
\hline
\end{tabular}


Table 3. Conversion of EB, yield of styrene and selectivities towards main products measured over the pristine and modified CMK-3 carbon replicas after 15 min. time-on-stream.

\begin{tabular}{|c|c|c|c|c|}
\hline Sample & $\begin{array}{l}\text { Conversion of } \\
\qquad \text { EB [\%] }\end{array}$ & $\begin{array}{c}\text { Yield of } \\
\text { styrene [\%] }\end{array}$ & $\begin{array}{l}\text { Selectivity to } \\
\text { styrene [\%] }\end{array}$ & $\begin{array}{l}\text { Selectivity to } \\
\qquad \mathrm{CO}_{\mathrm{x}}[\%]\end{array}$ \\
\hline \multicolumn{5}{|c|}{$\mathrm{O}_{2}:$ EB molar ratio $=1: 1$} \\
\hline CMK-3 & 22.6 & 21.4 & 94.5 & 3.9 \\
\hline CMK-3- $\mathrm{H}_{2} \mathrm{O}_{2}-10$ & 26.6 & 24.9 & 93.6 & 4.7 \\
\hline $\mathrm{CMK}-3-\mathrm{H}_{2} \mathrm{O}_{2}-20$ & 26.3 & 25.1 & 95.5 & 4.0 \\
\hline $\mathrm{CMK}-3-\mathrm{H}_{2} \mathrm{O}_{2}-30$ & 27.1 & 25.6 & 94.6 & 4.5 \\
\hline $\mathrm{CMK}-3-\mathrm{HNO}_{3}-20$ & 32.7 & 31.1 & 95.1 & 3.9 \\
\hline $\mathrm{CMK}-3-\mathrm{HNO}_{3}-40$ & 29.2 & 28.0 & 95.9 & 4.1 \\
\hline $\mathrm{CMK}-3-\mathrm{HNO}_{3}-65$ & 29.9 & 28.6 & 95.5 & 3.9 \\
\hline \multicolumn{5}{|c|}{$\mathrm{O}_{2}:$ EB molar ratio $=3: 1$} \\
\hline CMK-3 & 24.7 & 23.5 & 95.1 & 4.8 \\
\hline $\mathrm{CMK}-3-\mathrm{H}_{2} \mathrm{O}_{2}-10$ & 26.6 & 25.0 & 93.9 & 5.1 \\
\hline $\mathrm{CMK}-3-\mathrm{H}_{2} \mathrm{O}_{2}-20$ & 28.2 & 26.5 & 94.1 & 5.4 \\
\hline $\mathrm{CMK}-3-\mathrm{H}_{2} \mathrm{O}_{2}-30$ & 30.9 & 28.7 & 92.9 & 6.8 \\
\hline $\mathrm{CMK}-3-\mathrm{HNO}_{3}-20$ & 28.6 & 26.8 & 93.7 & 5.1 \\
\hline $\mathrm{CMK}-3-\mathrm{HNO}_{3}-40$ & 31.2 & 29.1 & 93.2 & 5.3 \\
\hline $\mathrm{CMK}-3-\mathrm{HNO}_{3}-65$ & 30.0 & 27.9 & 93.1 & 6.7 \\
\hline
\end{tabular}


Table 4. Distribution of oxygen-containing functionalities on the surface of fresh and spent catalysts determined by XPS (in brackets relative contents are presented).

\begin{tabular}{|c|c|c|c|c|c|}
\hline \multirow{2}{*}{\multicolumn{2}{|c|}{ Catalyst }} & \multicolumn{4}{|c|}{ Atomic concentration [\%] } \\
\hline & & $\mathrm{C}=\underline{\mathrm{O}}$ & $\underline{\mathrm{OH}}, \mathrm{COOH}$ & $\mathrm{COOH}$ & Sum \\
\hline \multirow{3}{*}{ CMK-3 } & fresh & $0.50(25 \%)$ & $1.33(66 \%)$ & $0.18(9 \%)$ & 2.01 \\
\hline & spent (1:1) & $2.33(40 \%)$ & $2.81(48 \%)$ & $0.68(12 \%)$ & 5.82 \\
\hline & spent $(3: 1)$ & $2.74(37 \%)$ & $3.72(51 \%)$ & $0.86(12 \%)$ & 7.32 \\
\hline \multirow{3}{*}{$\begin{array}{l}\text { CMK-3- } \\
\mathrm{H}_{2} \mathrm{O}_{2}-30\end{array}$} & fresh & $1.63(19 \%)$ & $6.31(73 \%)$ & $0.76(9 \%)$ & 8.70 \\
\hline & spent (1:1) & $2.78(34 \%)$ & $4.23(52 \%)$ & $1.11(14 \%)$ & 8.12 \\
\hline & spent $(3: 1)$ & $2.81(34 \%)$ & $4.24(52 \%)$ & $1.12(14 \%)$ & 8.17 \\
\hline \multirow{3}{*}{$\begin{array}{l}\mathrm{CMK}-3- \\
\mathrm{HNO}_{3}-65\end{array}$} & fresh & $2.09(22 \%)$ & $6.76(71 \%)$ & $0.66(7 \%)$ & 9.51 \\
\hline & spent $(1: 1)$ & $3.82(41 \%)$ & $4.49(48 \%)$ & $0.96(10 \%)$ & 9.27 \\
\hline & spent (3:1) & $3.01(37 \%)$ & $4.07(50 \%)$ & $1.10(13 \%)$ & 8.18 \\
\hline
\end{tabular}



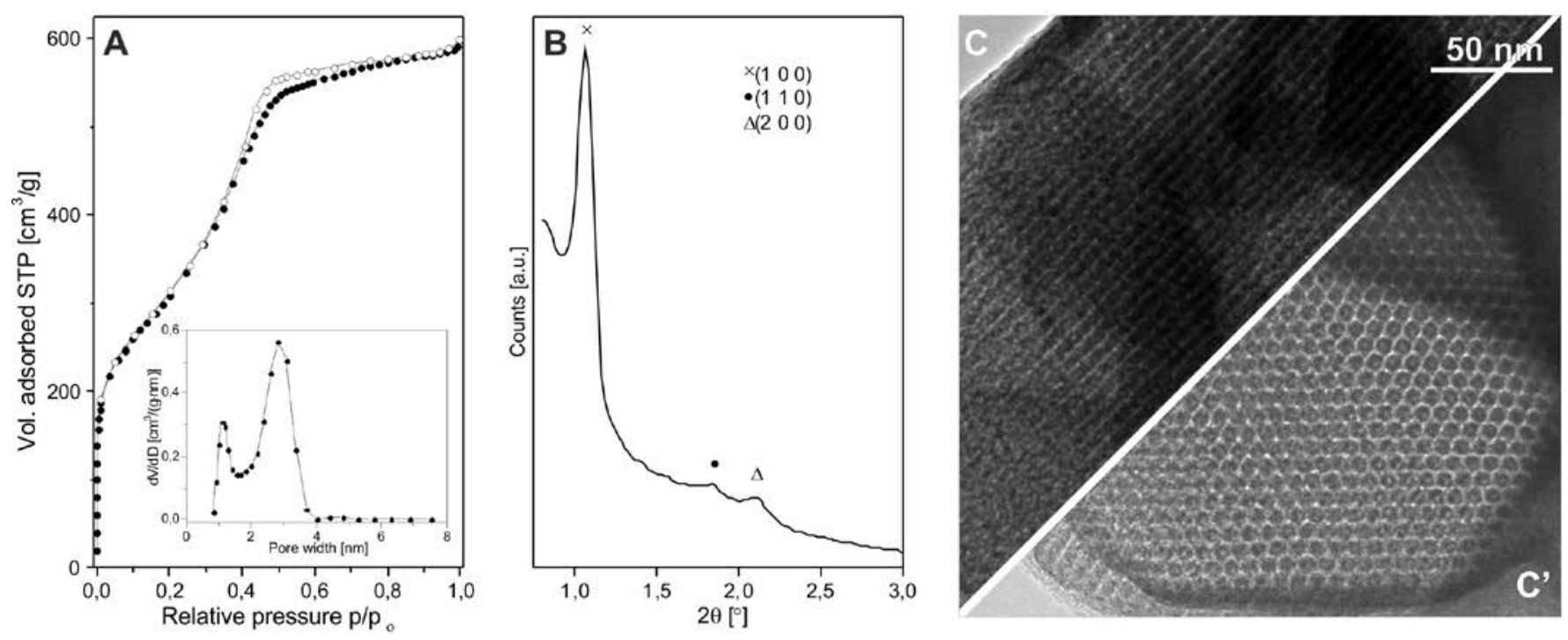

Fig. 1. Low-temperature $\mathrm{N}_{2}$ adsorption-desorption isotherm with pores size distribution calculated by QSDFT model (A), low-angle X-ray powder diffraction pattern (B) and TEM images taken parallel (C) and perpendicular to the pores $\left(\mathrm{C}^{\prime}\right)$ for the synthesized CMK-3 carbon replica. 


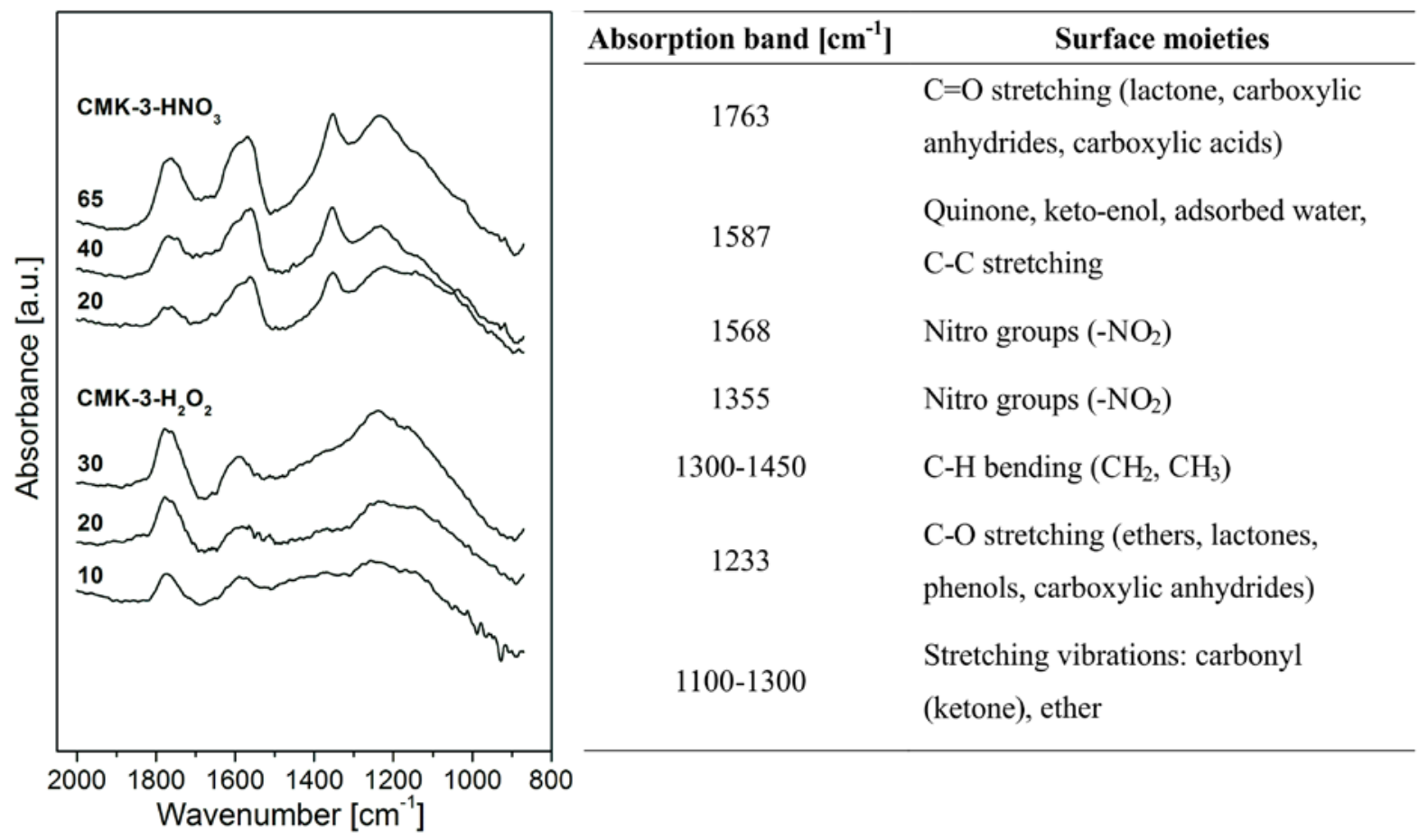

Fig. 2. DRIFT spectra collected for CMK-3 treated with oxidants (the spectrum of pristine CMK3 was subtracted as a background) and table of characteristic IR bands. 


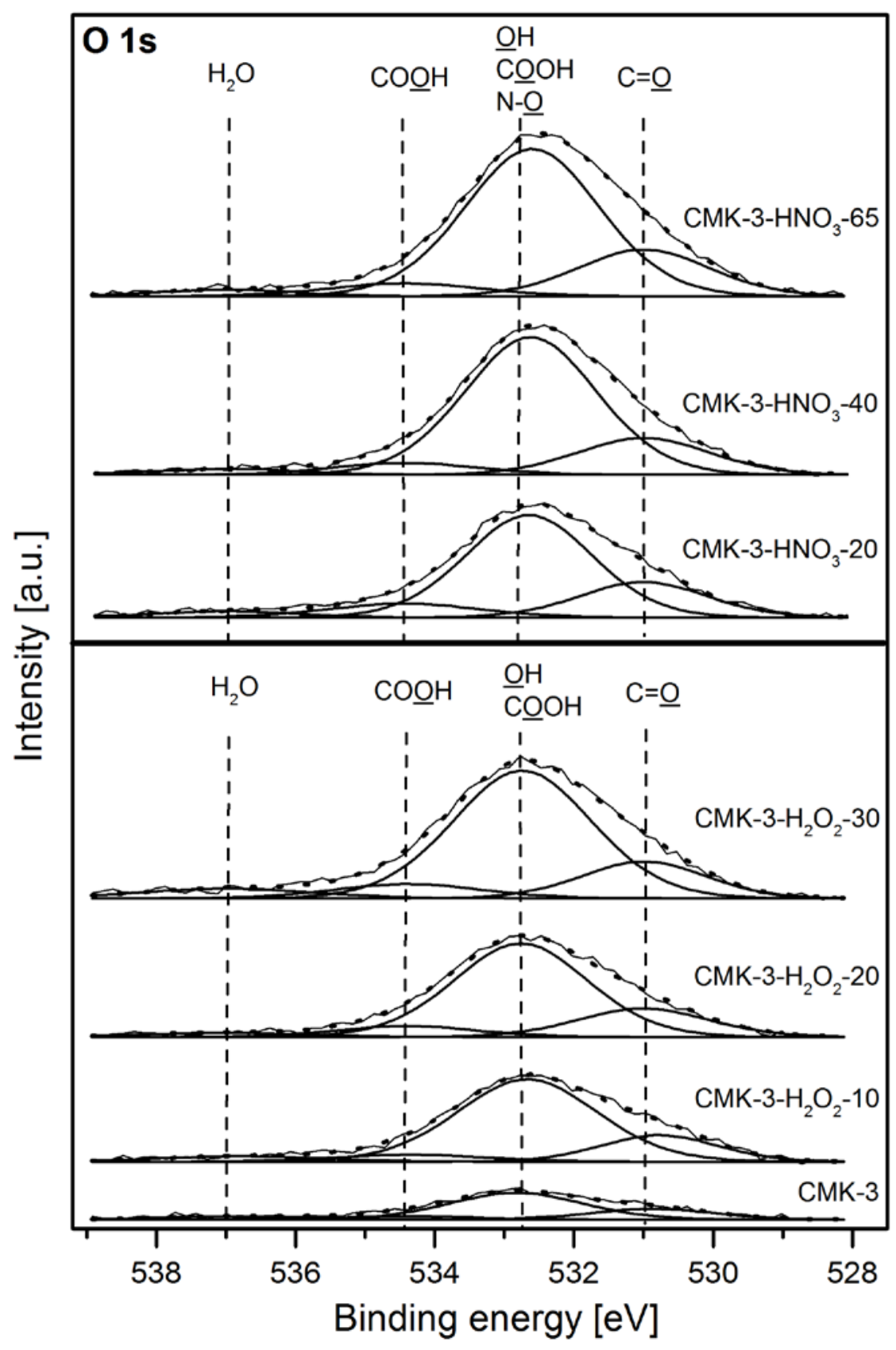

Fig. 3. High resolution O 1s photoelectron spectra of CMK-3 before and after activation with the oxidizing agents. 


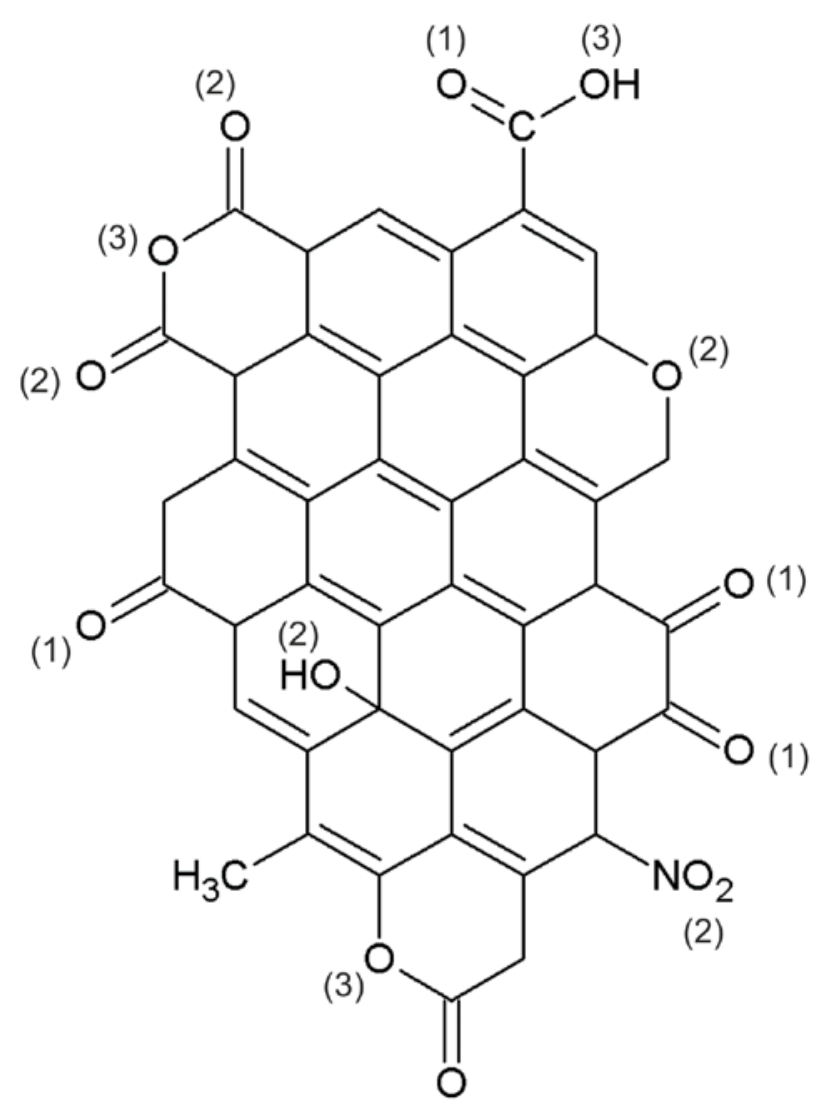

(2)

Fig. 4. A possible structure of surface groups present on the modified CMK-3 proposed on the basis of FTIR and XPS measurements. 


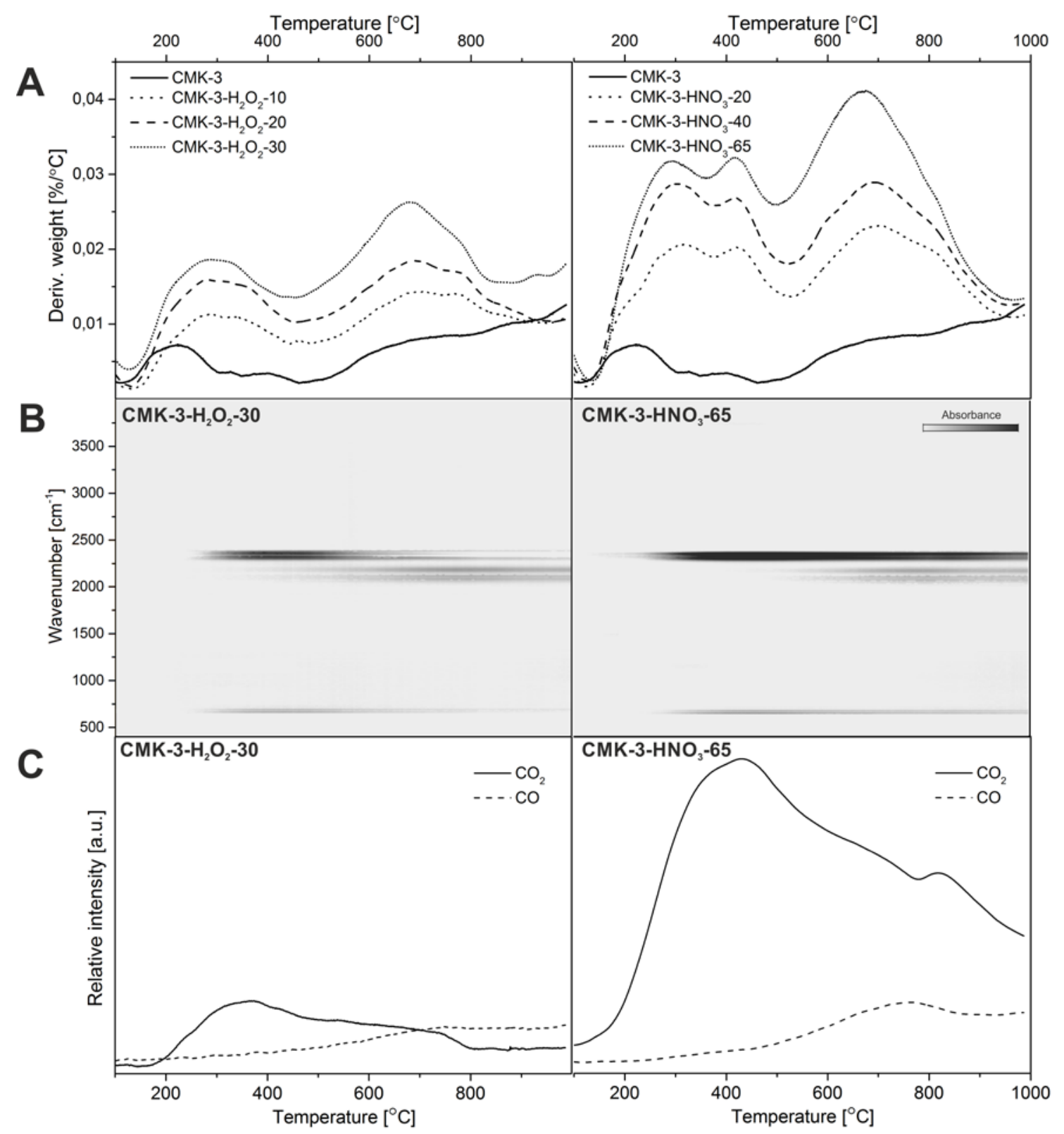

Fig. 5. DTG curves for the parent and modified CMK-3 (A), TG-FTIR maps for CMK-3- $\mathrm{H}_{2} \mathrm{O}_{2}-$ 30 and $\mathrm{CMK}-3-\mathrm{HNO}_{3}-65$ (B) and corresponding relative intensities of characteristic absorption bands for evolved gases $\left(\mathrm{CO}_{2}-2358 \mathrm{~cm}^{-1}\right.$ and $\left.\mathrm{CO}-2183 \mathrm{~cm}^{-1}\right)(\mathrm{C})$. 

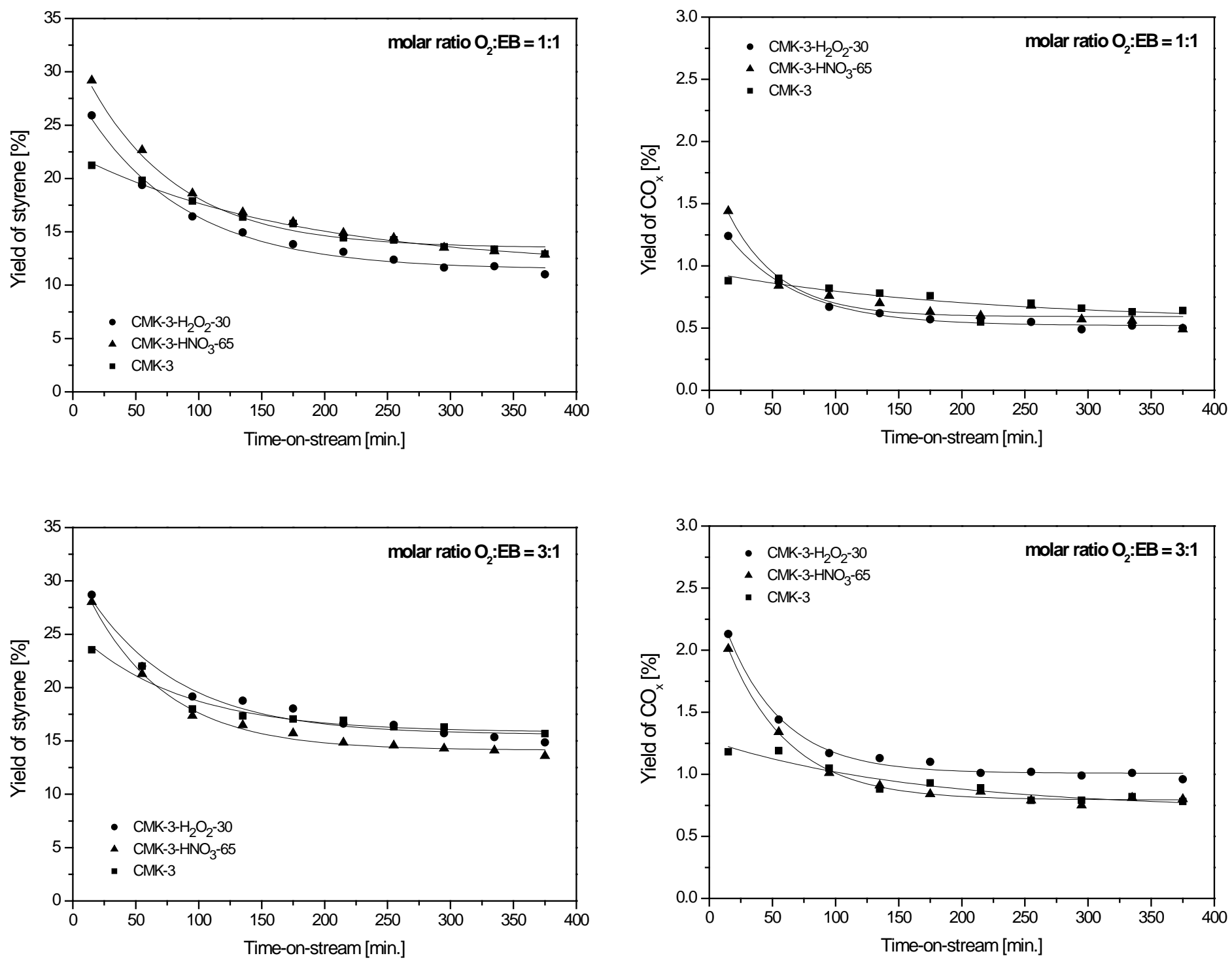

Fig. 6. Yield of styrene and $\mathrm{CO}_{\mathrm{x}}$ vs. time-on-stream observed at $350^{\circ} \mathrm{C}$ and the molar ratio of $\mathrm{O}_{2}: \mathrm{EB}=1.0$ and 3.0 over pristine CMK-3 and this replica modified with $\mathrm{H}_{2} \mathrm{O}_{2}(30 \%)$ and $\mathrm{HNO}_{3}$ (65\%). 


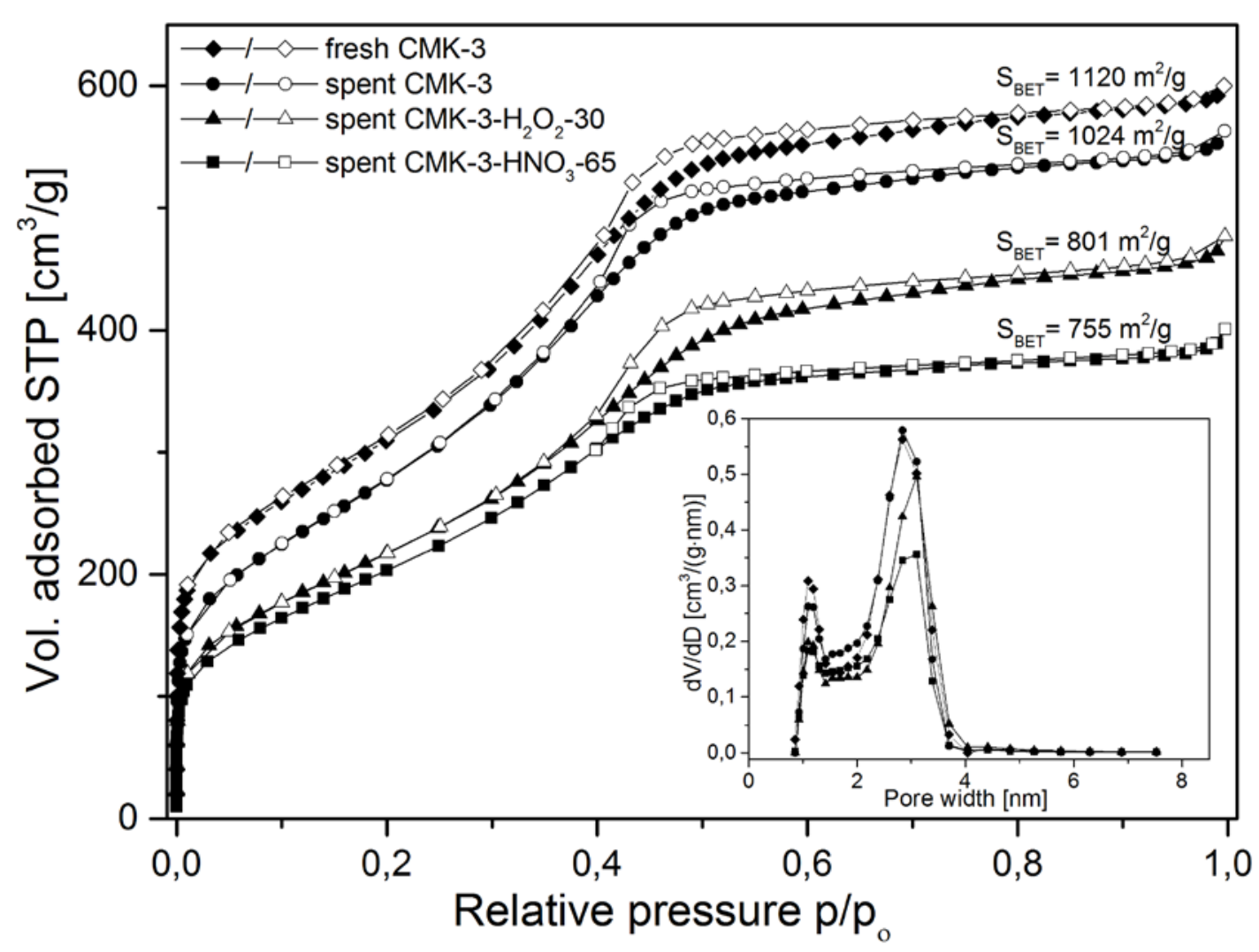

Fig. 7. $\mathrm{N}_{2}$ adsorption isotherms and pore size distributions for fresh CMK-3 and the spent catalysts (CMK-3, CMK-3- $\mathrm{H}_{2} \mathrm{O}_{2}-30$ and $\left.\mathrm{CMK}-3-\mathrm{HNO}_{3}-65\right)$ after 7 hours of time-on-stream at the molar ratio of $\mathrm{O}_{2}: \mathrm{EB}=1: 1$. 